\title{
Case Study: Use of Open Education Resources in Business Capstone
}

Mathien, Lorena D.

Business Department, State University of New York Buffalo State, United States

\begin{abstract}
Recent studies on textbook costs in the United States have indicated that there is a direct relationship between textbook costs and student success. With textbook costs increasing at a rate higher than the cost of living, many students have cited the textbook cost as an important factor when obtaining (or not obtaining) a textbook. Open educational resources (OER) are tools that educators can use to supplement or build a course. OER are free for anyone to reuse, revise, remix, and redistribute and are a low-cost, tailored solution for faculty and students. There have been calls for research that demonstrates how OER are being put into practice. This case study examines the responses of users to a voluntary survey in a capstone business course that implemented OER in lieu of traditional textbooks. The study suggests that, for teachers and students, as well as self-directed learners, OER provide a valuable resource to eliminate the pay wall, improve learning design, and support the power of the community through sharing and collaboration.
\end{abstract}

Keywords: OER; Open Education Resources; Business; Education, Case Study. 


\section{Introduction}

The growth of the open education resources (OER) movement has steadily gained global momentum since 2000 (Wiley \& Gurrell, 2009). OER offer opportunities to students who may be economically, or otherwise, excluded from formal education due the increasing cost of traditional learning materials. There are several studies and initiatives worldwide, and some of the claims indicate that OER and technology may be able to bridge the gap between formal and informal education (Ehlers, 2011; Meiszner, 2011). OER adoption may also lead to the inclusion of excluded groups of students via access to a wider range of little or no cost learning content (Lane, 2008).

The theory of OER was initially defined at the 2002 UNESCO Forum on the Impact of Open Courseware for Higher Education in Developing Countries (Armellini \& Nie, 2013). OER are teaching, learning, and research resources that reside in the public domain or have been released under a Creative Commons license that permit reuse or repurposing. These resources may include textbooks, course materials, modules, podcasts, experiments, demonstrations, teacher guides, lesson plans, videos, tests, images, supporting materials and resources, government documents, open datasets, programs, or full courses (Atkins, et al., 2007). Creative Commons licenses allow for the sharing of resources via the changing of copyright terms to best fit users' needs (Sharma, 2013). OER are free to use and remix, thus enabling instructors to customize and differentiate materials for students (Ash, 2012).

There have been several calls for research on the real-world effects of OER on instructors and learners (Schmidt-Jones, 2012). There is a "dearth of systematic empirical data to help answer the following questions: Who uses OER and for what purpose? What is the impact of OER? To what extent have OER engendered changes in teachers' professional practices? Have OER led to improvements in the quality of learning and outcomes?" (Kanwar, et al., 2010). This case study is the beginning of an empirical study on the impact of OER on business students.

\section{OER in SUNY Buffalo State Business Capstone}

\subsection{Purpose of Study}

According to the College Board 2011 study, the average postsecondary student at a fouryear college in the United States paid \$1,137 for textbooks during the 2010-2011 academic year. Since 1994, the cost of textbooks has risen nearly four times the rate of inflation (Student PIRGs, n.d.). Projected annual textbook costs in 2013 at the State University of New York (SUNY) two-year and four-year colleges was almost $\$ 417,000,000$, and textbook costs at SUNY Buffalo State were just over $\$ 11,000,000$ (IPEDS, n.d.). The need to understand the impact of these costs led to various studies, including the 2012 Florida 
Student Textbook Survey (Florida Virtual Campus, 2012) and the unpublished replicated study at SUNY Buffalo State. The purpose of these studies was to assess textbook choices, reasoning, and attitudes of students and faculty, including dollars spent, usage, impact of cost, formats preferred, functionality, and perceptions.

After implementing OER in the business capstone course, these studies were replicated and expanded to students across six sections of the course. Students were provided with free, modular-based learning materials via the campus learning management system from day one of the class. Previous and other sections of the course utilized traditional publisher materials. OER materials were all Creative Commons licensed, including readings, videos, images, and case studies, and offered free of charge to students.

Traditionally, the availability of OER materials has lagged in the business discipline. While offerings are being added regularly, lower-level introductory courses are more readily available. Upper-level courses have limited materials in comparison. This capstone course was adapted from a Saylor Academy course, and refined with the inclusion and exclusion of various OER, as well as instructor-developed assessments and assignments.

Those who actively use OER may be in the best position to judge its value. This is the first study done on this campus to assess OER satisfaction, and the first in the United States to assess satisfaction in an upper-level business course. This is an important first step in determining the quality and acceptability of OER in place of traditional textbook materials. SUNY has initiated a concerted effort, backed by state government, to engage and train faculty across New York State in the adoption and creation of OER. This study is in direct support of that initiative.

\subsection{Methodology}

At the end of each semester, undergraduate business capstone students were offered an anonymous, voluntary survey via Qualtrics ${ }^{\circledR}$ software. Students could opt in to the survey and the survey was not connected to final grades. Survey questions were adapted from the previous studies mentioned above. All questions were optional. Additional questions were added to assess the impact of OER on student learning outcomes. Ordinal Likert scales were used to measure perception of OER in the course, with open-ended questions used to probe deeper into responses. Data was then analyzed using descriptive statistics. The preliminary sample was 200 senior students. Table 1 outlines the respondent demographics. 
Table 1. Respondent Demographics

\begin{tabular}{llc}
\hline Demographic & Response Category & Percent \\
\hline Age & $<18$ & 0 \\
& $18-22$ & 58 \\
\multirow{2}{*}{ Gender } & $>22$ & 48 \\
& Male & 49 \\
Receive financial aid for texts & Female & 51 \\
& Yes & 31 \\
Total text cost covered by financial aid & Yes & 66 \\
& No & 19 \\
& No & 81 \\
\hline
\end{tabular}

Source: Mathien (2017).

\subsection{Results}

In terms of textbook format, previous research showed that students prefer a hard copy of their textbooks to digital; however, this study indicated that $93 \%$ of students consider cost to be the major factor when choosing a textbook (table 2). This was a key finding since many OER materials are offered digitally. While printing of materials is an option with OER, it does increase cost to the student.

Table 2. Student Textbook Preferences

\begin{tabular}{llc}
\hline Demographic & Response Category & Percent \\
\hline Factors for student choice of textbook & Cost & 93 \\
& Format & 2 \\
& Length of access & 5 \\
& New vs. used & 0 \\
Textbook format preferred by students & Digital & 7 \\
& Print & 29 \\
& Cheapest available & 62 \\
& No preference & 2 \\
Methods used to obtain textbooks & Bookstore - new/used & $69 / 76$ \\
& Outside source & 78 \\
& Rent - print/digital & $65 / 56$ \\
& Share with classmate & 44 \\
& Library - borrow/reserves & $22 / 11$ \\
\hline
\end{tabular}

Source: Mathien (2017). 
If the textbook was considered too expensive, $96 \%$ of students reported they have gone without a textbook for at least one course during their time at the college. Students responded that, at some time during their program of study, they have used various methods to obtain textbooks at a lower cost, including buying used, renting, sharing, or borrowing from the library (table 2). Other implications of textbook costs can be seen in figure 1.

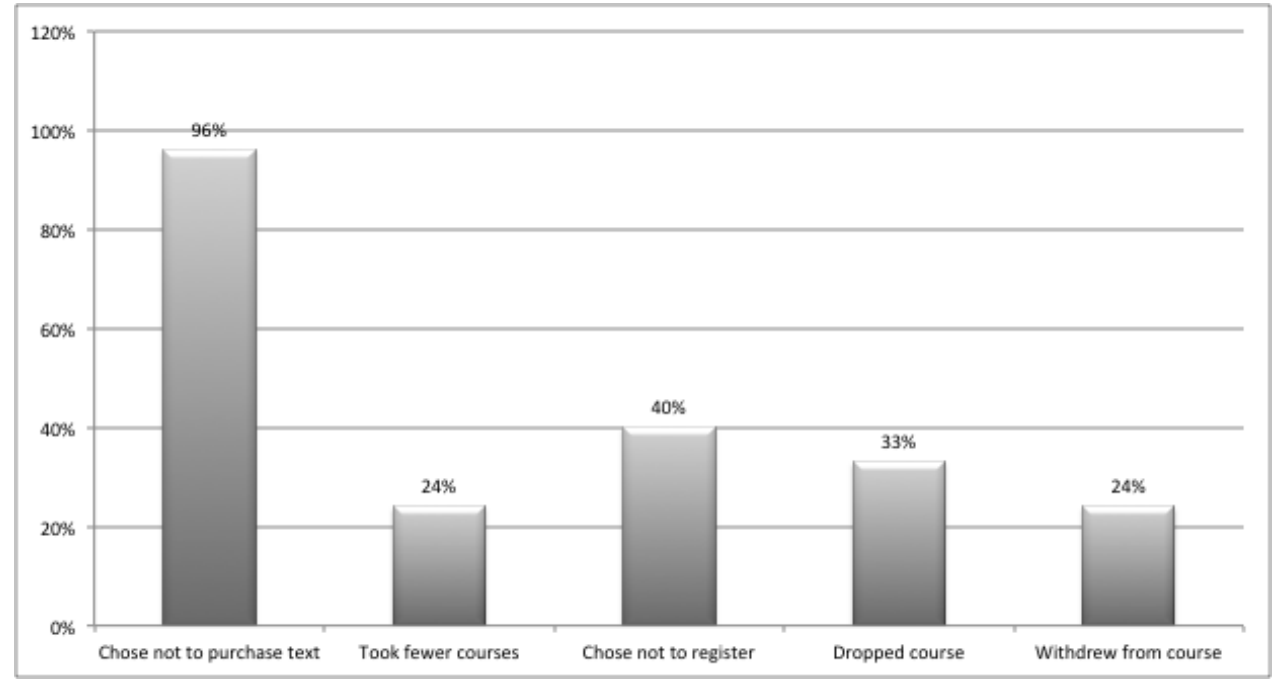

Figure 1. Impact of high textbook cost on student purchase behavior. Source: Mathien (2017).

Students were also asked about the effect of OER materials on their learning and engagement in the capstone course. While they reported positive outcomes in most categories, some of the most impactful results include increased participation in class, improved grades, increased engagement, increased experience with new ways of learning, and increased likeliness of completing readings and assignments (figure 2). Other positive findings include an increase in the interest of the subject being taught, increased student confidence, increased independence and self-reliance, increased collaboration with peers, increased enthusiasm for future study, increased interest in a wider range of subjects than before the OER, and better understanding of the content than use of a traditional textbook. 


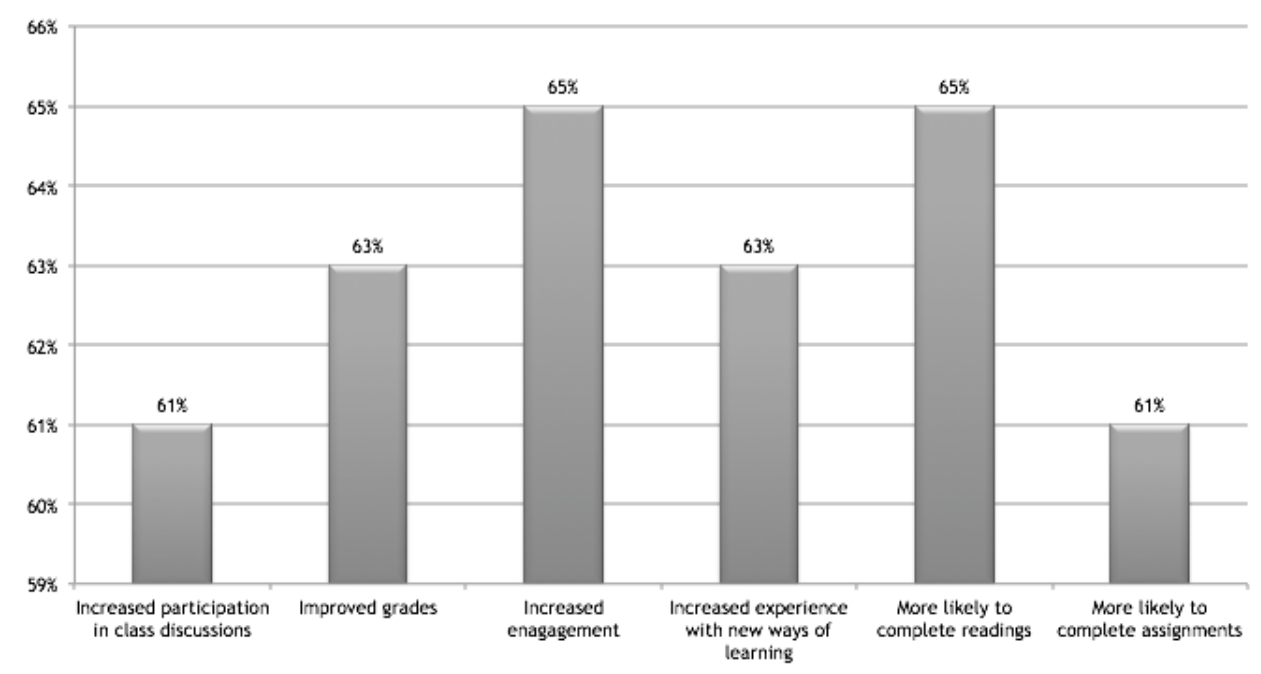

Figure 2. Impact of OER on student success. Source: Mathien (2017).

When students were asked if they saved money, $82 \%$ felt they had, while only $6 \%$ felt they had not. No reason was indicated as to why they did not save money, although course materials were free. When asked if they would take more OER courses, 79\% indicated they definitively would take more and $18 \%$ said they might take more OER courses.

\section{Conclusion and Recommendations}

Studies have shown that the cost of textbooks is leading to reduced textbook purchases and decreased performance in courses. Students are foregoing the text or even dropping the course due to the increasing cost of course materials. While faculty are using various methods to try to control costs, OER are an effective way to cut expenses and add value to a course. Benefits of OER for the student may include day-one access to course materials, lower cost, and improved learning. Benefits for faculty may include better-prepared students, as well as control over and increased engagement with learning materials. Benefits may also extend to the institution, including potential increased enrollment and greater persistence and retention.

This study investigated the impact of OER on students in various sections of a capstone course at SUNY Buffalo State. Results strongly indicate increased satisfaction with the course materials, as well as several measures of improved performance. With day-one access to course materials, and flexibility to adjust materials as needed, the materials are more current than traditional publisher materials that typically see a lag from time of development to time of publication. The business discipline is in constant change, and OER 
allow for easy and quick customization of content to remain current. Students in this capstone course indicated a preference for use of OER for several reasons, and most were highly satisfied with the course materials.

This study measured the student perceptions of OER by understanding how students perceive the quality of OER compared to traditional materials. Further research could expand this study to other business courses and institutions, and include faculty perception of OER as well. Additional analyses could be done by comparing groups of students statistically to assess differences between groups. In addition, further quantitative analyses could be conducted to measure the impact of OER adoption on cost. The data for this analysis was collected, but proceeding data before adoption would need to be assessed. While saving money is important, concern for education outcomes is critical. Further research may be conducted on grades, course throughout rates (combination of drop rates, withdraw rates, and final grades), and enrollment intensity and persistence (credit attempts and completions).

\section{References}

Armellini, A., \& Nie, M. (2013). Open educational practices for curriculum advancement. Open Learning: The Journal of Open, Distance and e-Learning, 28(1), 7-20.

Ash, K. (2012). Open educational resources surge. Education Week's Digital Directions, 6, $42-45$.

Atkins, D., Seely Brown, J., \& Hammond, A. (2007). A review of the open educational resources (OER) movement: Achievements, challenges, and new opportunities. San Francisco, CA: William and Flora Hewlett Foundation.

Ehlers, U. (2011). Extending the territory: From open education resources to open educational practices. Journal of Open, Flexible and Distance Learning, 15(2), 1-10.

Florida Virtual Campus. (2012). 2012 Florida student textbook survey. Tallahassee, FL: Author.

IPEDS: https://nces.ed.gov/ipeds/Home/UseTheData

Kanwar, A., Kodhandaraman, B., Umar, A. (2010). Toward sustainable open education resources: A perspective from the global south. The American Journal of Distance Education, 24(2), 65-80.

Lane, A. (2008). Widening participation in education through open education resources. In T. Iiyoshi \& M.S. Vijay Kumar (Eds.), Opening up education: The collective advancement of education through open technology, open content, and open knowledge (pp. 149-163). Cambridge, MA: MIT Press. 
Meiszner, A. (2011). The why and how of open education - With lessons from the openSE and openED projects ( $1^{\text {st }}$ ed.). Maastricht: UNU-MERIT \& CCG.

Schmidt-Jones, C. (2012). An open educational resource supports a diversity of inquirybased learning. The International Review of Research in Open and Distance Learning, 13(1), 1-16.

Sharma, Y. (2013). Open access and creative commons - A new platform for open educational resources and scientific research. Current Science, 105(11), 1461.

Student PIRGS: https://studentpirgs.org/

Wiley, D., \& Gurrell, S. (2009). A decade of development. Open Learning: The Journal of Open, Distance and e-Learning, 24, 11-21. 